\title{
Oral Nano-Insulin Therapy: Current Progress on Nanoparticle-Based Devices for Intestinal Epithelium-Targeted Insulin Delivery
}

Aiman Ahmad, lekhsan Othman, Anuar Zaini and Ezharul Hoque Chowdhury*

Jeffrey Cheah School of Medicine and Health Sciences, Monash University (Sunway Campus), Jalan Lagoon Selatan, Malaysia

\begin{abstract}
Extensive research has been carried out to explore the potential ways of orally delivering insulin for the treatment of diabetes. Advancements in nanotechnology have brought the scientific community ever closer to this goal. The current review focuses on the various barriers existing in the route of oral insulin delivery and the strategies undertaken so far to overcome those by harnessing nanoparticles as potential vehicles of insulin. Additionally, an overview on the performance of various nanoparticle formulations including polymeric as well as lipid-based preparations will be given in context to their levels of success for insulin delivery through the intestinal epithelium. Finally, future prospects on nano-insulin therapy will be discussed.
\end{abstract}

Keywords: Insulin; Nanoparticles; Oral delivery; Diabetes; Chitosan; Poly( $\Gamma$-Glutamic Acid); Poly(Lactide-Co-Glycolide); Poly(Acrylic Acid); Poly(Isobutylcyanoacrylate); Poly(Alkylcyanoacrylate); Poly(Ethylene Glycol); Vitamin B12; Wheat germ agglutinin; Lectin; Solid lipid nanoparticles; Tight junction

Abbreviations: NP: Nanoparticle; CS: Chitosan; $\gamma$ pga: Poly $(\gamma-$ Glutamic acid); DTPA: Diethylene triamine pentaacetic acid; TMC: N-Trimethyl chitosan; CSK: CSKSSDYQC targeting ligand; Cys: Cysteine; HTCC: N-(2-hydroxyl) Propyl-3-trimethyl ammonium chitosan; PLGA: Poly(lactide-co-glycolide); PL: Phospholipid; HP55: Hydroxypropyl methylcellulose phthalate; RS: Eudragit ${ }^{\circ}$ RS; PAA: Poly(acrylic acid); PIBCA: Poly(isobutylcyanoacrylate); PACA: Poly(alkylcyanoacrylate); MAA: Methacrylic acid; PEG: Poly(ethylene glycol); AA: Acrylic acid; P(MAA-g-PEG): Copolymer of poly(ethylene glycol)-grafted methacrylic acid; P(AA-g-PEG): Copolymer of poly(ethylene glycol)-grafted acrylic acid; PEGDMA: Poly(ethylene glycol) dimethacrylates; PLA-F127-PLA: PLA-b-Pluronic-b-PLA; PCL: Poly( $\varepsilon$-caprolactone); VB12: Vitamin B12; DPPC: Dipalmitoylphosphatidylcholine; WGA: Wheat germ agglutinin; TL: Tomato lectin; UEA1: Ulex Europaeus Agglutinin 1; NaTC: Sodium taurocholate; SLN: Solid lipid nanoparticles; WGA-N-glut-PE: Wheat Germ AgglutininN-glutaryl-phosphatidylethanolamine; TJ: Tight junction; BA: Relative bioavailability; PA: Relative Pharmacological Bioavailability.

\section{Introduction}

\section{Oral administration of insulin}

Oral administration of drugs is generally preferred due to the advantages it confers as a painless, simple mode of delivery, in order to increase patient compliance to the therapy. Orally administered medications would be particularly beneficial in managing chronic diseases such as diabetes, which requires life-long therapy [1-5].

Due to the inconvenience of daily injections, insulin therapy, currently given though subcutaneous (SC) injections in diabetic patients [6-8] has led to problems with patient compliance [6,9]. Furthermore insulin administered orally enters the portal circulation and passes through the liver before reaching the systemic circulation, which closely resembles the physiological insulin secretion, as opposed to conventional SC insulin, which can lead to peripheral hyperinsulinemia and its associated complications $[6,10,11]$.

Thus oral formulations for insulin would greatly benefit patients with diabetes requiring insulin therapy. However insulin is inherently unstable in the gastrointestinal (GI) tract and has low permeability to cross the intestinal epithelium $[6-8,12,13]$.

\section{Uptake of drugs and particles in the GI tract}

Particles in the GI tract can be absorbed through various sites and mechanisms. Those with a diameter of $1 \mu \mathrm{m}$ may be phagocytosed by intestinal macrophages, whereas smaller particles $(<10 \mu \mathrm{m})$ may be absorbed through the Peyer's patches in the small intestine. NPs smaller than $200 \mathrm{~nm}$ can be transported via endocytosis by enterocytes. Although rare and possibly dangerous, larger particles $(5-150 \mu \mathrm{m})$ can be taken up by villus tips by a passive process known as persorption. The factors affecting particle uptake include the particle size, surface charge or hydrophobicity, amount or concentration, as well as any incorporated targeting mechanisms on the particle that would express affinity to certain sites in the GI tract [14].

\section{Obstacles to oral insulin delivery}

The function of the GI system includes the digestion and absorption of nutrients, as well as acting as a defense barrier to pathogenic microorganisms and toxins $[6,15]$. As a result, numerous challenges exist for oral delivery, limiting the bioavailability of the drugs. In order to enter the bloodstream, orally administered drugs should be able to withstand the chemical and enzymatic conditions in the GI system, and be able to cross the mucus layering the enterocytes before diffusing through the intestinal epithelium (Figure 1) [6].

Extreme pH conditions and proteolytic enzymes: GI $\mathrm{pH}$ conditions range from the acidic gastric environment ( $\mathrm{pH} 1.2-3.0$ ) to the slightly basic intestinal environment $(\mathrm{pH} 6.5-8.0)[6,16]$. This

${ }^{*}$ Corresponding author: Ezharul Hoque Chowdhury, Jeffrey Cheah School of Medicine and Health Sciences, Monash University (Sunway Campus), Jalan Lagoon Selatan, Bandar Sunway, Selangor Darul Ehsan, Malaysia, Tel: +6035514 4978; Fax: +603-5514 6323; E-mail: md.ezharul.hoque@monash.edu

Received February 25, 2012; Accepted March 17, 2012; Published March 31, 2012

Citation: Ahmad A, Othman I, Zaini A, Chowdhury EH (2012) Oral NanoInsulin Therapy: Current Progress on Nanoparticle-Based Devices for Intestinal Epithelium-Targeted Insulin Delivery. J Nanomedic Nanotechnol S4:007. doi:10.4172/2157-7439.S4-007

Copyright: $\odot 2012$ Ahmad A, et al. This is an open-access article distributed under the terms of the Creative Commons Attribution License, which permits unrestricted use, distribution, and reproduction in any medium, provided the original author and source are credited. 
Citation: Ahmad A, Othman I, Zaini A, Chowdhury EH (2012) Oral Nano-Insulin Therapy: Current Progress on Nanoparticle-Based Devices for Intestinal Epithelium-Targeted Insulin Delivery. J Nanomedic Nanotechnol S4:007. doi:10.4172/2157-7439.S4-007

is particularly damaging for drugs such as insulin, a polypeptide, which would lose its activity due to $\mathrm{pH}$-induced oxidation, hydrolysis or deamidation (Figure 1) [6,13]. Furthermore, protein drugs would be acted upon by proteolytic enzymes present in the GI lumen (e.g. pepsin, trypsin, chymotrypsin, elastase, carboxypeptidases) (Figure 1 ), as well as those associated with enterocytes (membrane-bound aminopeptidases and cytosolic proteases such as insulin-degrading enzyme) [6,17-19].

Mucus layer: In addition, drug molecules in the intestine must cross the GI mucus barrier in order to be absorbed though the epithelial layer (Figure 1). Mucus is a complex hydrogel made up of proteins (mainly mucins), carbohydrates, lipids and salts, as well as other components (e.g. antibodies, cellular debris, etc.). This semipermeable mucus layer obstructs the diffusion of protein molecules from approaching the epithelial cells. This diffusion barrier is due to the molecules in mucus forming an obstructing mesh, the constant turnover of mucus in the GI tract, and the electrostatic repulsion between the negatively charged mucus layer and anionic protein molecules [6,20-23].

Intestinal epithelium: Intestinal epithelium also presents as a barrier to drug absorption (Figure 1). Particle size, surface charge or hydrophobicity, and the nature of the polymer used, affect the transport across epithelial layers [1,24].

Passive diffusion via the transcellular route is limited to small lipophilic drugs (molecular weight under $700 \mathrm{Da}$ ) [6,25]. Most protein drugs exceed $3000 \mathrm{Da}$ and hence, are difficult to be absorbed this way $[6,13,26]$. Intercellular tight junctions (TJs) prevent most paracellular transport of drugs, with the exception of hydrophilic drug molecules weighing less than $200 \mathrm{Da}$. It is virtually impossible for proteins to be transported via the paracellular route without permeation enhancers [6,27-29].

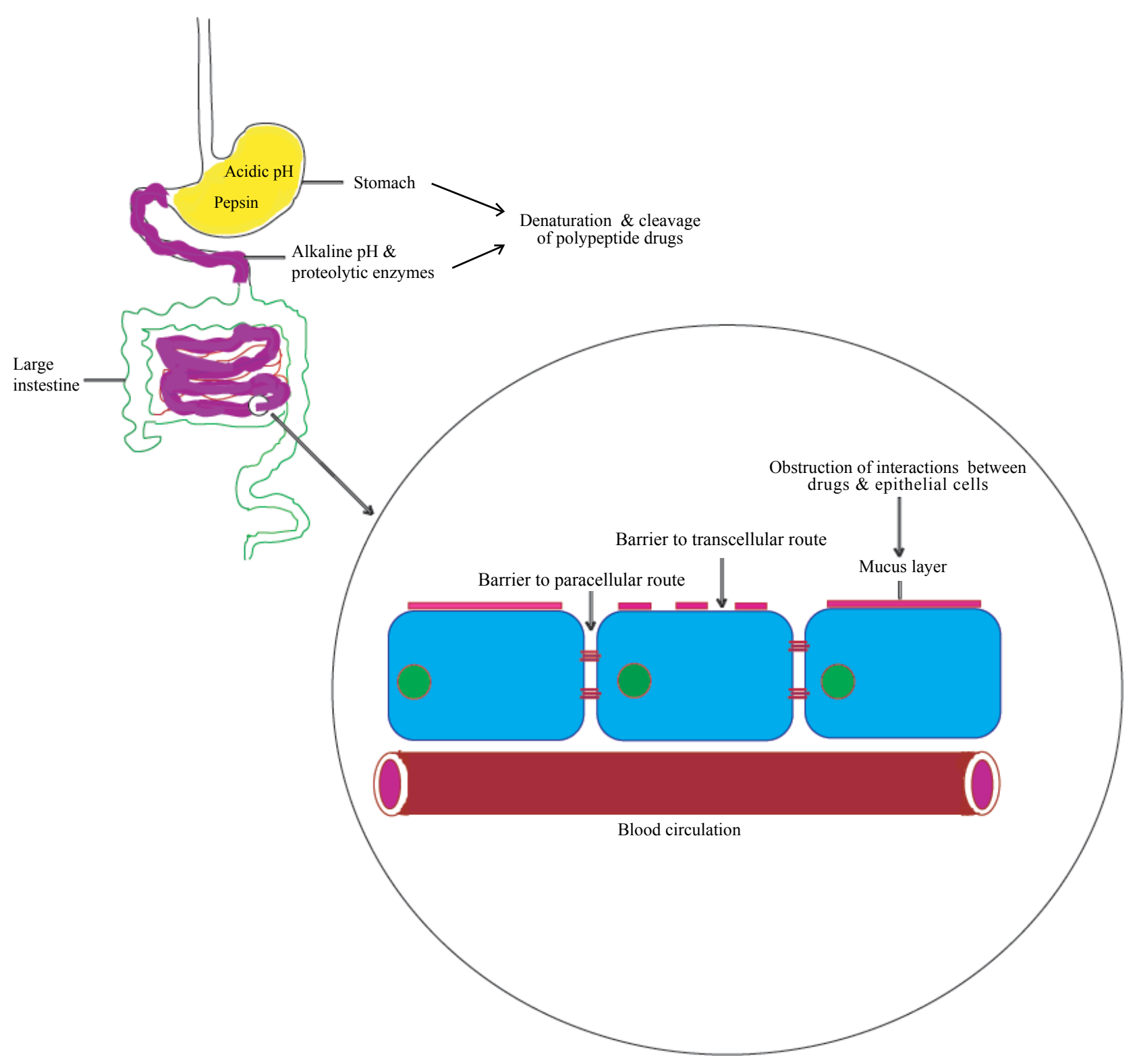

Figure 1: Major barriers to oral delivery of peptide- and protein-based drugs. 
Citation: Ahmad A, Othman I, Zaini A, Chowdhury EH (2012) Oral Nano-Insulin Therapy: Current Progress on Nanoparticle-Based Devices for Intestinal Epithelium-Targeted Insulin Delivery. J Nanomedic Nanotechnol S4:007. doi:10.4172/2157-7439.S4-007

Page 3 of 10

\section{Role of nanoparticles in oral insulin therapy}

Nanoparticles (NPs) are widely used as drug delivery vehicles with extensive research being made to date for harnessing the benefits of different NP formulations for oral insulin delivery (Figure 2). NPs include nanospheres (having a uniform distribution of drug within a matrix) and nanocapsules (consisting of a polymer membrane encapsulating the drug in a cavity) $[1,30]$.

Efficient transport along GI tract: NP formulations can potentially improve the traffic of oral insulin in the GI track due to: (i) protection against $\mathrm{pH}$-related and enzymatic degradation in the GI tract by encapsulation of insulin within NP carriers (Figure 2), (ii) better drug delivery close to absorption sites - via increased residence times near intestinal epithelium by mucoadhesive coating of NPs and gradual release of insulin close to the epithelial layer (Figure 2) and, (iii) improved transport through the GI mucus layer by way of mucuspenetrating particles or coatings $[1,6,20,24,31]$.

Mucoadhesion of polymeric particles may result from one or more of the following: (i) hydrogen-bonding, (ii) electrostatic forces, (iii) hydrophobic interactions, (iv) van der Waals forces, or (v) entanglement of polymer chains with mucins $[1,20,32]$.

Free drug molecules or drug-loaded NPs may be absorbed by the intestinal epithelium. Stable NPs made from polymers insoluble in water (e.g. PLGA) are more likely to be absorbed intact. On the other hand, NPs composed of less stable polyelectrolyte complexes (e.g. CS) will undergo partial dissociation without being absorbed intact [1].

Therefore, the bioavailability, efficacy and specificity of drugs can be improved with the use of NPs $[1,33]$. However, it is vital that NPs do not cause toxicity, immune reactions, inflammation, thrombosis, and are biodegradable [1,24,30,33-35].

Facilitated transcellular transport: NPs can be taken up by the intestinal epithelial cells via different mechanisms, depending on the constituent polymers. Transcellular transport of NPs is mainly by energy-dependent endocytic processes [6,36]. These encompass phagocytosis (largely by M cells of Peyer's patches), macropinocytosis and micropinocytosis. Micropinocytosis is further divided into clathrin-mediated, caveolin-mediated, as well as clathrin- and caveolinindependent endocytosis. Among these mechanisms, phagocytosis and clathrin-mediated endocytosis are receptor-mediated $[1,6]$.

Non-specific cellular uptake: NP uptake by cells might involve non-specific processes, which depend on particle diameter, surface charge and mucoadhesivity [6,37]. Substances exhibiting mucoadhesive properties include chitosan (CS), poly(acrylic acid) (PAA), thiomers and their derivatives, all of which are hydrophilic [6,38-41]. Adhesion and absorption of particles by intestinal epithelial cells are also increased when coated with polyvinyl alcohol (PVA) and vitamin $\mathrm{E}$ succinylated polyethylene glycol 1000 (Vitamin E TGSP) [6,24].

Specific cellular uptake: This occurs on NPs modified with

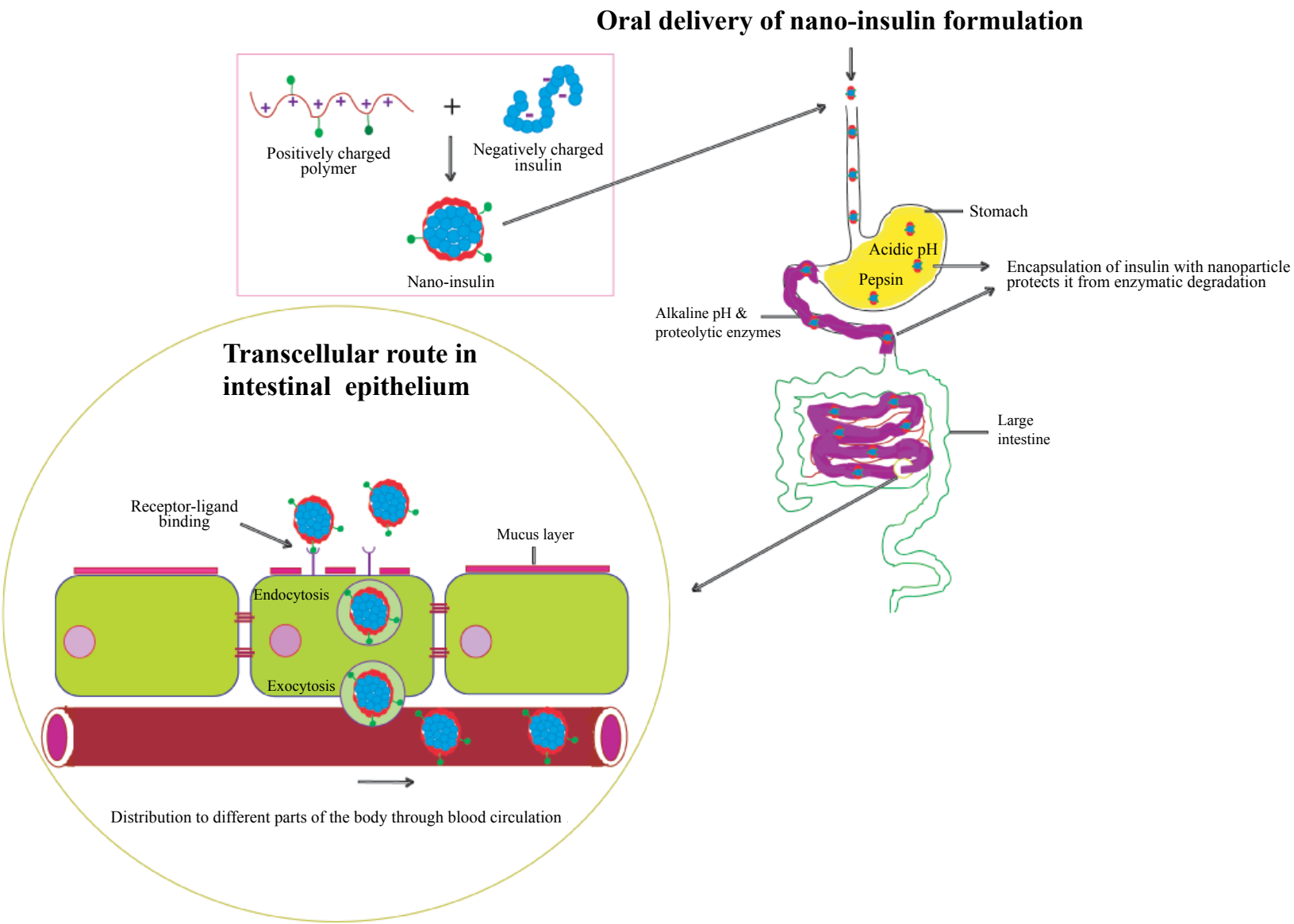

Figure 2: An ideal approach based on a nano-insulin formulation for overcoming barriers in the oral route. 
ligands (e.g. vitamins or proteins) to target specific cells (Figure 2) [6]. These targeted NPs are mostly taken up by clathrin-mediated endocytosis $[1,36,37,42]$. For example, conjugating vitamin B12 to NPs has been shown to improve the transport of proteinaceous drugs via specific receptor recognition by enterocytes [6,43-47]. Lectins, which are proteins or glycoproteins involved in cellular recognition and adhesion, can also be conjugated to NPs to promote specific uptake [20]. Lectins have affinities to specific sugars, and lectin-modified NPs were described to have better bioadhesivity, endocytosis, and resistance to digestion [6,20,48-51]. Wheat germ agglutinin (WGA), a lectin, has been proven to bind to the surface of Caco-2 cells and enterocytes. WGA demonstrates affinity to N-acetyl-D-glucosamine and sialic acid, which are present along the intestinal tract. In addition, WGA is transported via receptor-mediated endocytosis, involving the epidermal growth factor receptor, which is widely expressed on the surface of enterocytes $[6,20,52]$.

M cells of Peyer's patches may also be employed for targeted delivery of NPs. It has been shown that fluorescent microparticles can be absorbed rapidly into the mesenteric lymph (within 5 min of administration), albeit in small amounts $[53,54]$. Coating of particles with certain antibodies may potentially enhance $M$ cell absorption [53,55].

Enhanced paracellular transport: Molecules larger than $1 \mathrm{~nm}$ are blocked by the intercellular TJs [6,56], hence, these junctional complexes must be reversibly opened by polymers and calcium chelators to allow transport between adjacent epithelial cells. These polymers include CS (cationic) and PAA (anionic), together with their derivatives, which induce a cascade of reactions that eventually result in TJ disassembly. On the other hand, calcium chelators disrupt TJs via activation of protein kinase C $[1,6,57]$.

\section{Development of Nanoparticle Formulations for Delivering Insulin to Intestinal Epithelium}

NP carriers must have a balance of characteristics to allow effective insulin delivery. Their size should be small enough to allow diffusion and uptake, but large enough to carry a favorable amount of insulin. Mucoadhesion prolongs the residence time of NPs at absorption sites, but can hinder diffusion through the GI mucus layer [1]. Various formulations have been tested, and some subsequently modified to find the right composition for efficient oral delivery of insulin. These are summarized in Table 1.

\section{Polymeric nano-carriers}

Chitosan (CS): A cationic polysaccharide synthesized by partial deacetylation of chitin (polymer found in crustacean shells and insects) [6,91], consists of glucosamine and $\mathrm{N}$-acetyl-glucosamine, with varying proportions depending on the degree of deacetylation $[6,92]$.

NP carriers composed of CS are more effective to transport insulin than the simple solutions of CS and insulin. CS/insulin NPs caused prolonged hypoglycemia in diabetic rats, unlike the solution form $[6,58]$. CS is mucoadhesive due to its inherent cationic charges, thus exhibiting electrostatic attraction with the negatively-charged mucus (due to the presence of sialic-acid groups in mucin) [6,93]. Furthermore, CS-based nano-carriers have the ability to cause reversible opening of TJs, increasing paracellular permeation through intestinal epithelium. This phenomenon has been proven in Caco- 2 cell monolayers, whereby actin filaments redistribution and transepithelial electrical resistance (TEER) reduction were observed [6,10,59-61]. The reversible disruption of TJs involves CLDN4 degradation and re-synthesis, although it is likely that other mechanisms exist $[6,94]$. However, this increase in paracellular permeability is likely to be safe since it did not result in increased absorption of lipopolysaccharide (LPS), which is a common toxin found within the GI tract. This indicates that TJ disruption is not associated with increased permeability to endotoxins [95].

Modifications of CS NP preparations, NP formulations consisting of CS and poly $(\gamma$-glutamic acid) ( $\gamma$ PGA) were studied for oral insulin therapy. These $\mathrm{CS} / \gamma \mathrm{PGA}$ NPs were $\mathrm{pH}$-sensitive and increased insulin absorption in the intestine. Results displayed a slow onset, prolonged hypoglycemia in diabetic rats, with a relative bioavailability (compared to SC insulin) of $15 \%$, but increased to $20 \%$ if the NPs were in entericcoated capsules $[6,10,60,62,63]$. When CS and $\gamma$ PGA were blended with tripolyphosphate (TPP) and $\mathrm{MgSO}_{4}$, multi-ion-crosslinked NPs were formed. These are more compact, stable over broader $\mathrm{pH}$ ranges, and more capable of transporting insulin than simple NPs [59]. Studies suggest that insulin transported in $\mathrm{CS} / \gamma \mathrm{PGA}$ NPs may be used as alternatives to SC basal intermediate-acting insulin [10].

A recent study investigated a further modification of $\mathrm{CS} / \gamma \mathrm{PGA}$ NPs by covalent conjugation of diethylene triamine pentaacetic acid (DTPA) to $\gamma$ PGA. DTPA acts by chelation of metal cations, including calcium and zinc ions. As a result, chelation of $\mathrm{Ca}^{2+}$ causes $\mathrm{TJ}$ disruption, enhancing paracellular permeability. Since intestinal metallo-peptidases in the lumen as well as on the brush border require certain metallic ions (e.g. $\mathrm{Ca}^{2+}$ and $\mathrm{Zn}^{2+}$ ) in their structure for enzymatic function, chelation of these cations by DTPA inhibits their proteolytic activity. As a result, CS $/ \gamma$ PGA-DTPA NPs increased insulin relative oral bioavailability to $20 \%$ (in comparison to SC insulin), causing prolonged hypoglycemia in diabetic rats [64].

Chitosan derivatives: The favorable mucoadhesive and T] opening properties of CS are lost at pH 7.4 due to loss of solubility as a result of deprotonation of amino groups present in CS at neutral/ basic $\mathrm{pH}$ ranges $[6,96]$. In order to improve the characteristics of $\mathrm{CS}$, its chemical structure has been altered to form derivatives, including $\mathrm{N}$-trimethylated CS (TMC), thiolated CS and N-(2-hydroxyl) propyl-3trimethyl ammonium CS (HTCC), which have been tested as potential carriers for oral insulin $[6,66,67,69,97,98]$.

TMC NPs: TMC is synthesized by conjugation of trimethyl groups to the amino groups in CS, which increases its solubility in neutral/ basic $\mathrm{pH}$ conditions. A TMC and $\gamma$ PGA NP formulation has been shown to open TJs in Caco-2 cells, improving paracellular insulin transport. Additionally, TMC $/ \gamma$ PGA NPs allow insulin absorption along the entire intestinal tract, instead of being limited to areas with $\mathrm{pH}$ values close to the $\mathrm{p}^{\mathrm{Ka}}$ of CS ( 6.5), as exhibited by CS/ $/$ PGA NPs $[6,65]$.

TMC NPs can be further modified to include a targeting ligand, CSKSSDYQC (CSK), which specifically recognizes goblet cells. Since goblet cells are the second most common intestinal epithelial cell, TMC-CSK NPs are potentially useful carriers for oral insulin delivery. Experimental results involving goblet cell-like HT29-MTX cells show that uptake mechanisms of TMC NPs and TMC-CSK NPs involve active transport and electrostatic interaction. The addition of the CSK ligand further enhanced absorption via clathrin- and caveolae- mediated endocytosis. Thus, TMC-CSK NPs produced a greater hypoglycemic effect with an increased relative bioavailability by 1.5 -fold compared to unmodified TMC NPs [66].

Thiolated CS NPs: These contain attached thiol groups and can form covalent bonds with mucin glycoproteins via thiol-disulfide 
Citation: Ahmad A, Othman I, Zaini A, Chowdhury EH (2012) Oral Nano-Insulin Therapy: Current Progress on Nanoparticle-Based Devices for Intestinal Epithelium-Targeted Insulin Delivery. J Nanomedic Nanotechnol S4:007. doi:10.4172/2157-7439.S4-007

Page 5 of 10

\begin{tabular}{|c|c|c|c|c|}
\hline \multicolumn{2}{|c|}{ NP formulation } & Experimental model & Observation & Reference \\
\hline \multirow[b]{3}{*}{ o } & CSNPS & $\begin{array}{l}\text { Diabetic rats; } \\
\text { Caco-2 cell monolayer }\end{array}$ & $\begin{array}{l}\text { Prolonged hypoglycemia; } \\
\text { TJ opening effect }\end{array}$ & $\begin{array}{l}{[6,58]} \\
{[6,10,59-61]}\end{array}$ \\
\hline & CS- $\gamma$ PGANPS & Diabetic rats & $\begin{array}{l}\text { Prolonged hypoglycemia; } \\
\text { BA } 15 \% \text { ( } 20 \% \text { when the NPs were enteric- } \\
\text { coated) }\end{array}$ & {$[6,10,60,62,63]$} \\
\hline & CS/YPGA-DTPANPS & Diabetic rats & $\begin{array}{l}\text { Prolonged hypoglycemia; } \\
\text { BA } 20 \%\end{array}$ & {$[64]$} \\
\hline \multirow{4}{*}{ 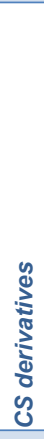 } & TMC/YPGANPS & Caco-2 cell monolayer & TJ opening effect & {$[6,65]$} \\
\hline & TMC-CSKNPS & $\begin{array}{l}\text { Caco-2/HT29-MTX co-culture; } \\
\text { Diabetic rats }\end{array}$ & $\begin{array}{l}\text { Enhanced absorption via clathrin- and caveolae- } \\
\text { mediated endocytosis; } \\
\text { Greater hypoglycemic effect; } \\
\text { Increase BA by } 1.5 \text {-fold (compared to unmodified } \\
\text { TMC NPs) }\end{array}$ & {$[66]$} \\
\hline & TMC-Cys NPs & $\begin{array}{l}\text { Caco-2 cell monolayer; } \\
\text { Rat intestinal model }\end{array}$ & Improved absorption & {$[6,67,68]$} \\
\hline & HTCC NPS & In vitro & TJ opening effect & [69] \\
\hline \multirow[b]{5}{*}{$\frac{\pi}{\sqrt{0}}$} & $\begin{array}{l}\text { PLGANPs loaded with } \\
\text { insulin-PL complex }\end{array}$ & Diabetic rats & BA $7.7 \%$ & {$[6,70]$} \\
\hline & PLGA-HP55 NPS & Diabetic rats & BA $6.27 \%$ & {$[6,71,72]$} \\
\hline & $\begin{array}{l}\text { PLGA/RS NPS (in HP55- } \\
\text { coated capsules) }\end{array}$ & Diabetic rats & $\begin{array}{l}\text { Prolonged hypoglycemia; } \\
\text { Pharmacological availability } \sim 9.2 \%\end{array}$ & [73] \\
\hline & $\begin{array}{l}\text { Antacid-incorporated PLGA } \\
\text { NPs }\end{array}$ & Diabetic rats & $\begin{array}{l}\text { Oral bioavailability } 6 \text { times higher than native } \\
\text { insulin }\end{array}$ & [74] \\
\hline & CS-PLGANPS & Diabetic rats & $\begin{array}{l}\text { Greater bioadhesion; } \\
\text { PA } 10.5 \%\end{array}$ & [75] \\
\hline \multirow{5}{*}{  } & PAA-Cys NPs & Diabetic rats & $\begin{array}{l}\text { Increase in mucoadhesivity; } \\
2.3 \text {-fold increase in area under the curve of } \\
\text { insulin }\end{array}$ & {$[6,76]$} \\
\hline & PIBCANPS & Diabetic rats & $\begin{array}{l}\text { Significant increase in absorption; } \\
\text { Prolonged hypoglycemia }\end{array}$ & {$[77]$} \\
\hline & PACANPS & Diabetic rats & Prolonged hypoglycemia (36 h) & [78] \\
\hline & $\begin{array}{l}\text { P(MAA-g-PEG) and P(AA- } \\
\text { g-PEG) NPs }\end{array}$ & Diabetic rats & $\begin{array}{l}\text { Protected insulin at low } \mathrm{pH} ; \\
\text { Prolonged hypoglycemic }(>6 \mathrm{~h}) \\
\text { Up to } 50 \% \text { glucose reduction }\end{array}$ & [79] \\
\hline & $\begin{array}{l}\text { poly(PEGDMA:MAA) } \\
\text { microparticles }\end{array}$ & Diabetic rats & $\begin{array}{l}\text { pH-sensitive; } \\
\text { Prolonged hypoglycemia }(8-10 \text { h) }\end{array}$ & {$[80]$} \\
\hline \multirow[b]{2}{*}{ ত্র } & PLA-F127-PLA NPS & Diabetic mice & Prolonged hypoglycemia (23 h) & {$[6,82,83]$} \\
\hline & & & & \\
\hline 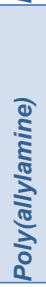 & $\begin{array}{l}\text { Insulin-poly(allylamine) } \\
\text { NPs }\end{array}$ & $\begin{array}{l}\text { Caco-2 cell monolayer; } \\
\text { In vitro }\end{array}$ & $\begin{array}{l}\text { Reduced pepsin, trypsin and chymotrypsin } \\
\text { degradation; } \\
\text { Improved transcellular and paracellular } \\
\text { transport; } \\
\text { TJ opening effect }\end{array}$ & {$[6,84-86]$} \\
\hline
\end{tabular}




\begin{tabular}{|c|c|c|c|c|}
\hline 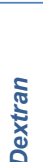 & VB12-dextran NPs & Diabetic rats & $\begin{array}{l}\text { Prolonged hypoglycemia }(54 \mathrm{~h}) ; \\
\text { 70-75\% blood glucose reduction; } \\
\text { PA } 29.4 \%\end{array}$ & {$[6,45-47]$} \\
\hline \multirow{3}{*}{ 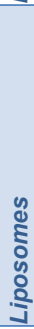 } & DPPC/cholesterol & Normal \& diabetic rats & $\begin{array}{l}\text { Greater hypoglycemic effect; } \\
\text { Protection against degradation in the GI tract } \\
\text { and entered the bloodstream intact }\end{array}$ & [87] \\
\hline & $\begin{array}{l}\text { WGA-, TL- and UEA1- } \\
\text { modified liposomes }\end{array}$ & Normal rats \& diabetic mice & $\begin{array}{l}\text { Hypoglycemic effect; } \\
\text { BA 9.12\% (WGA), } 7.89 \% \text { (TL) and } 5.37 \% \\
\text { (UEA1) }\end{array}$ & [88] \\
\hline & NaTC liposomes & Normal mice & Greater hypoglycemic effect & [89] \\
\hline & $\begin{array}{l}\text { Cetyl palmitate-based } \\
\text { SLNs }\end{array}$ & Diabetic rats & $\begin{array}{l}\text { Prolonged hypoglycemia }(24 \mathrm{~h}) \text {; } \\
\text { PA } 5.1 \%\end{array}$ & {$[6,90]$} \\
\hline$\sum_{n}^{\infty}$ & $\begin{array}{l}\text { (WGA-N-glut-PE)-modified } \\
\text { SLNs }\end{array}$ & $\begin{array}{l}\text { In vitro; } \\
\text { Normal ratS }\end{array}$ & $\begin{array}{l}\text { Greater protection against enzymatic } \\
\text { degradation; } \\
\text { PA } 6.08 \%\end{array}$ & [51] \\
\hline
\end{tabular}

Table 1: Oral insulin nano-carriers and experimental results relating to each.

exchange reactions, resulting in increased mucoadhesion. A thiolated CS preparation, TMC-Cys is formed by linking Cys via amide bonds to primary amino groups on TMC. When used as nano-carriers, TMCCys improved absorption of orally administered insulin in Caco-2 cells and rat intestinal models. Moreover, TMC-Cys NPs showed no evidence of toxicity in biocompatibility assessments $[6,67,68]$.

HTCC NPs: A form of quaternized CS, HTCC, was shown to exhibit greater cationic charge density, increased mucoadhesion, as well as TJ opening ability. The disruption of TJs occurred via the binding of HTCC to zona-occludens proteins and redistribution of actin filaments. Moreover, ELISA results indicated that the activity of insulin was preserved in HTCC microparticles, and 3-(4,5-dimethylthiazol2-yl)-2,5-diphenyltetrazolium bromide (MTT) assays proved that the microparticles were non-cytotoxic [69]. Hence, HTCC carriers may also be used to aid oral insulin delivery.

Poly(lactide-co-glycolide) (PLGA): PLGA particles are known to be biocompatible $[6,99]$. Insulin has been combined with soybean phosphatidylcholine to form insulin-phospholipid complex which can be loaded into PLGA NPs. This oral preparation managed to cause prolonged hypoglycemia ( $42.6 \%$ blood glucose reduction) in diabetic rats for up to $12 \mathrm{~h}$ post-administration. Relative bioavailability (compared to SC insulin) was 7.7\% [6,70].

The burst effect of insulin release can be alleviated by different preparations of PLGA formulations including a star-branched form of PLGA, $\beta$-cyclodextrin-PLGA ( $\beta$-CD-PLGA), as well as PLGAhydroxypropyl methylcellulose phthalate (PLGA-HP55). PLGA-HP55 NPs was used to deliver insulin with a relative bioavailability of $6.27 \%$ in diabetic rats $[6,71,72]$.

PLGA and Eudragit ${ }^{\circledR}$ RS NPs: Another study reported on the manufacturing of NPs composed of PLGA and Eudragit ${ }^{\circ}$ RS (RS), a polycationic mucoadhesive acrylic polymer $[6,73]$. These PLGA/ RS NPs containing insulin were filled in hard gelatin capsules coated with HP55, a pH-sensitive polymer. This led to a two-stage delivery mechanism. First, the HP55-coated capsules protected the NPs against low $\mathrm{pH}$ and enzymatic damage in the gastric environment. Second, the mucoadhesive PLGA/RS NPs attached to intestinal epithelium and released insulin. RS contains positively-charged ammonio-methyl groups that can attach to mucus. The NPs may also be able to open TJs to release insulin that can be absorbed paracellularly. The resulting effect is prolonged hypoglycemia in diabetic rats, with a pharmacological bioavailability of insulin around 9.2\% [73].

Antacid-incorporated PLGA NPs: Since insulin has been reported to be unstable in PLGA microparticles due to deamidation, antacids (e.g. magnesium hydroxide, magnesium carbonate or zinc carbonate) can be incorporated to form antacid-insulin co-encapsulated PLGA NPs. This method of preparation preserved the structure of insulin, and protected it under simulated gastric and intestinal fluids. The antacidincorporated NPs exhibited an oral bioavailability 6 times higher compared to native insulin, and caused dose-dependent hypoglycemia in diabetic rats [74].

CS-PLGA NPs: Recently, PLGA NPs have been cationically modified by coating them with CS, since the anionic surface charge of PLGA limits its oral bioavailability. CS-PLGA NPs had greater bioadhesion and improved the relative pharmacological activity of oral insulin (compared to SC) from 7.6\% (in PLGA NPs) to 10.5\% (in CSPLGA NPs). MTT assays proved that there was no increased toxicity as well. These improved characteristics by the CS coating might allow CSPLGA nano-formulations to be successful as oral insulin nano-carriers [75].

Acrylic-based polymers and copolymers: Evidence suggests that poly(acrylic acid) (PAA) and thiomers show mucoadhesive properties $[6,100,101]$. An experiment combining these two materials to form thiolated PAA-based particles, in the form of PAA-Cys NPs as vehicles for oral insulin, caused hypoglycemia in diabetic rats. There was also 2.3-fold increase in the area under the curve of insulin with PAA-Cys compared to unaltered PAA particles. This suggests that thiolation of PAA increases its mucoadhesive properties $[6,76]$.

Poly(isobutylcyanoacrylate) (PIBCA) nano-dispersions is another nano-carrier tested for oral insulin delivery, which showed statistically significant increase in absorption in PIBCA-encapsulated insulin, compared to that of native insulin [77]. Other forms of poly(alkylcyanoacrylate) (PACA) NPs dispersed in microemulsion was also tested for administering insulin intragastrically to diabetic rats, causing considerable hypoglycemia for up to $36 \mathrm{~h}$ [78]. 
Acrylic-based hydrogels exhibit different levels of efficacy for insulin transport depending on their network structure formed during the polymerization process. A study showed that P(MAA-g-EG) hydrogels had the maximum bioavailability when prepared using the least amount of solvent [102].

Gel nanospheres were manufactured containing crosslinked networks of methacrylic acid (MAA) or acrylic acid (AA), both grafted with poly(ethylene glycol) (PEG). These P(MAA-g-PEG) and P(AA-gPEG) nanospheres were used to deliver insulin orally in diabetic rats. The entrapped insulin was protected at low $\mathrm{pH}$, and released at neutral $\mathrm{pH}$ conditions. Hypoglycemic effects on diabetic rats lasted for at least $6 \mathrm{~h}$. In addition, amongst the gel nanosphere formulations investigated, P(AA-g-PEG) prepared from a molar ratio of 2:1 AA:EG caused the most hypoglycemia (almost 50\% glucose reduction) [79].

Another acrylic-based hydrogel used in the oral delivery of insulin is in the form of microparticles based on copolymerization of PEG dimethacrylate (PEGDMA) with MAA. PEG of various molecular weights $(400-4000 \mathrm{~g} / \mathrm{mol})$ were used in the synthesis of poly(PEGDMA:MAA). These hydrophilic, pH-sensitive poly(PEGDMA:MAA) microparticles held on to insulin at acidic conditions ( $\mathrm{pH}$ 2.5) and released insulin at neutral/basic environments ( $\mathrm{pH}$ 7.4). When administered to diabetic rats, prolonged hypoglycemia was observed up to 8-10 h. The copolymers made from the heaviest PEG substrate (molecular weight of $4000 \mathrm{~g} / \mathrm{mol}$ ) exhibited the highest efficiency in insulin transport, since with larger molecular weights, microparticles had a decrease in cross-linking density, greater hydrophilicity, and hence, higher insulin loading capacity [80].

Poly(lactide) (PLA): PLA-b-Pluronic-b-PLA (PLA-F127-PLA) vesicles were tested as insulin delivery vehicles, orally administered to diabetic mice. Hypoglycemia lasted for $23 \mathrm{~h}$, with a maximum glucose reduction at $4.5 \mathrm{~h}[6,103]$. Pluronic block copolymers contain polyethylene oxide blocks which are attracted to the small intestine. They are also amphiphilic, and thus, able to pass through cell membranes $[6,81]$.

Poly( $\boldsymbol{\varepsilon}$-caprolactone) (PCL): NPs made up of PCL (polyester) and Eudragit $^{\oplus}$ RS have been successfully tested for oral insulin delivery. Insulin in its regular hexameric form, as well as a monomeric insulin analog (aspart-insulin), was tested using this NP preparation. Insulin activity was preserved and a reduction in hyperglycemia was induced, with maximum effect $8 \mathrm{~h}$ post-administration. However, the effect on blood glucose level was greater with the NPs containing aspart-insulin $(-52 \%)$ than the NPs with regular insulin $(-24 \%)$, suggesting that aspart-insulin is absorbed more effectively $[6,82,83]$.

Poly(allylamine): These polymers are amphiphilic and can incorporate insulin by forming nano-complexes. These NPs are able to minimize enzymatic degradation of insulin by pepsin, trypsin and chymotrypsin in vitro. Additionally, transcellular and paracellular transport of insulin across Caco-2 cell monolayers were improved with the latter being via reversible disruption of TJs [6,84-86].

Dextran: Dextran conjugated to vitamin B12 has been used for targeted delivery of oral insulin. Vitamin B12 complexes with intrinsic factor (IF) in the intestine, and is recognized by IF-specific receptors on enterocytes. Results indicated better transport, in the form of higher pharmacological availability, of NPs made up of dextran-B12 compared to unmodified dextran. Hypoglycemia was detected, lasting for $54 \mathrm{~h}[6,45-47]$.

\section{Lipid-based nano-formulations}

Liposomes: Liposomes are made up of concentric lipid bilayers, interspersed with aqueous spaces, are able to protect molecules entrapped within them $[87,104]$. Insulin loaded into liposomes composed of egg phosphatidylcholine/cholesterol and phosphatidylinositol mildly reduced blood glucose levels in rats [87].

Dipalmitoyl-phosphatidylcholine (DPPC)/cholesterol liposomes managed to cause more significant hypoglycemia in normal and diabetic rats. DPPC liposomes also offered some protection against degradation within the GI tract and entered the bloodstream intact [87].

Modified liposome preparations: Studies on modification of liposomes have been carried out which showed improvements in its stability within the GI environment. Sugar chain portions of mucin and PEG were used as surface coatings on liposomes, to form MucinLip and PEG-Lip, both of which were loaded with insulin and orally administered to rats. Surface-modified liposomes, when compared to uncoated liposome preparations, were better able to survive digestion against bile salts in the GI tract and also caused a gradual but more sustained hypoglycemic effect [105].

Lectins such as wheat germ agglutinin (WGA), tomato lectin (TL) and Ulex europaeus agglutinin 1 (UEA1) can be incorporated into liposomes containing insulin, in order to target specific sites on intestinal epithelium. WGA is known to attach to Caco-2 cell membranes and taken up by endocytosis, whereas TL exhibits resistance to enzymatic action in the intestine, as well as having affinity to rat intestinal mucosa. On the other hand, UEA1 has been shown to have specificity to $\mathrm{M}$ cells of Peyer's patches in mice. When included in the preparation of insulin-containing liposomes, WGA-, TL- and UEA1-modified liposomes caused hypoglycemia in rats, with relative bioavailabilities of $9.12 \%, 7.89 \%$ and $5.37 \%$ respectively (compared to SC insulin). No hypoglycemia was observed with unmodified insulincontaining liposomes [88].

Permeation enhancers (e.g. sodium taurocholate, NaTC) can be incorporated into the insulin-liposome preparation. NaTC is known to disrupt TJs, enhancing paracellular transport. Insulin-NaTC liposomes caused larger glucose reductions in mice compared with insulin liposomes [89].

Solid lipid nanoparticles (SLNs): Cetyl palmitate-based SLNs have been loaded with insulin and orally administered to diabetic rats, with a relative pharmacological bioavailability of 5.1\% (compared to SC insulin) and caused significant hypoglycemia over $24 \mathrm{~h}[6,90]$. Another study investigated lectin-modified SLNs as insulin carriers, in which the SLNs were modified with wheat germ agglutinin-N-glutarylphosphatidylethanolamine (WGA-N-glut-PE). In comparison with insulin-loaded SLNs, WGA-modified SLNs exhibited greater protection for insulin against enzymatic degradation in vitro, as well as increased its relative pharmacological bioavailability (compared to SC administration) from $4.46 \%$ (in SLNs) to $6.08 \%$ (in WGA-modified SLNs) [51].

Other lipid-based formulations: A delivery vehicle made up of a polyelectrolyte complex of insulin-CS, dispersed in a water-in-oil microemulsion, was tested on diabetic rats. This formulation protected the incorporated insulin from enzymatic degradation in simulated gastric environments. The biological activity of insulin was preserved 
and prolonged hypoglycemia was observed in diabetic rats receiving the oral preparation [106].

\section{Other nanoparticle formulations}

Multilayered NPs: A complex multilayered NP preparation made of a hydrogel consisting of alginate, dextran sulfate and poloxamer 188, was successfully manufactured. Insulin was incorporated into the hydrogel, stabilized by CS and coated with albumin [107-109]. Poloxamers, also known as pluronic block copolymers, are made up of hydrophilic poly(ethylene oxide) and hydrophobic poly(propylene oxide) blocks, and have the ability to increase drug solubility and transport in the intestine $[1,110,111]$.

In vitro studies on this complex hydrogel formulation showed that the preparation procedure maintained the bioactivity of insulin. Moreover, the characteristics of the insulin-NP complex could be adjusted depending on minute variations of reactant concentrations. Reducing the concentrations of calcium ions while increasing poloxamer and albumin concentrations resulted in smaller NPs. Reduction in albumin content, however, improved insulin entrapment and retention when exposed to simulated gastric conditions. The authors concluded that the optimum proportions of the components were $0.20 \%$ calcium chloride, $0.06 \%$ alginate, $0.04 \%$ dextran sulphate, $0.04 \%$ poloxamer $188,0.006 \%$ insulin, $0.07 \% \mathrm{CS}$ and $0.5 \%$ albumin [107].

Further studies on this multilayered NP formulation showed that insulin was protected against enzymatic digestion and its absorption enhanced. Insulin transport was increased by the NP preparation (compared to free insulin) as much as 2.1-fold through Caco-2 cell monolayer, 3.7-fold through Caco-2/HT29 co-culture (mucus secreting), and 3.9-fold through rat intestinal models. This resulted in sustained ( $>24 \mathrm{~h}$ ) hypoglycemia (up to $40 \%$ of basal levels) in diabetic rats, as well as $13 \%$ bioavailability $[108,109]$.

\section{Conclusion}

There are great benefits of successful oral insulin delivery, in terms of its ease and simplicity, improved patient compliance, ultimately leading to better patient outcome. Thus, tremendous efforts have been made to develop the best oral insulin delivery device. Nanotechnology has provided a promising platform for engineering such insulin carriers.

Nevertheless, it is important to note that experimental results involving the use of animal models need to be interpreted with care, due to the differences between the anatomy and physiology of laboratory animals and humans. For example, compared to humans, rats and mice produce less mucin. Rodents also have a less acidic gastric fluid. Furthermore, there may be other differences that would significantly affect the transport of the many NP carriers tested so far [20,112-115].

To date, there have been no approved oral insulin nanoformulations. This is probably due to the difficult requirements that need to be met by the drug preparations. In order to be successful, orally administered insulin nano-carriers must be able to increase insulin bioavailability to reach therapeutic levels, with minimal variation amongst different individuals, as well as having a financially feasible manufacturing process for mass production [1]. Another potential problem is that high insulin doses may induce mitogenic changes in the GI epithelium since insulin is a growth factor [6,7]. In other words, an efficient delivery system should require lower insulin doses to achieve therapeutic hypoglycemic effects [6].
Possible future directions in oral insulin research include alterations to insulin in order to achieve greater stability $[6,8,12]$, as well as combination therapy where insulin substitutes (e.g. glucagon-like peptide 1 and exenatide) may be co-administered with insulin for more effective glycemic control but with fewer side effects $[6,116]$. Since there have been many new investigations and discoveries of potential NPs to administer insulin orally, and these formulations are continuously being improved, the future of oral insulin looks promising.

\section{References}

1. Plapied L, Duhem N, des Rieux A, Préat $V$ (2011) Fate of polymeric nanocarriers for oral drug delivery. Curr Opin Colloid Interface Sci 16: 228-237.

2. Bromberg $L$ (2008) Polymeric micelles in oral chemotherapy. J Control Release 128: 99-112.

3. Yamanaka YJ, Leong KW (2008) Engineering strategies to enhance nanoparticle-mediated oral delivery. J Biomater Sci Polym Ed 19: 1549-1570.

4. Gaucher G, Satturwar P, Jones MC, Furtos A, Leroux JC (2010) Polymeric micelles for oral drug delivery. Eur J Pharm Biopharm 76: 147-158.

5. Ruenraroengsak P, Cook JM, Florence AT (2010) Nanosystem drug targeting Facing up to complex realities. J Control Release 141: 265-276.

6. Chen MC, Sonaje K, Chen KJ, Sung HW (2011) A review of the prospects for polymeric nanoparticle platforms in oral insulin delivery. Biomaterials 32 9826-9838.

7. Brogden RN, Heel RC (1987) Human insulin. A review of its biological activity pharmacokinetics and therapeutic use. Drugs 34: 350-371.

8. Galloway JA, Chance RE (1994) Improving insulin therapy: achievements and challenges. Horm Metab Res 26: 591-598.

9. Chin RL, Martinez R, Garmel G (1993) Gas gangrene from subcutaneous insulin administration. Am J Emerg Med 11: 622-625.

10. Sonaje K, Lin KJ, Wey SP, Lin CK, Yeh TH, et al. (2010) Biodistribution, pharmacodynamics and pharmacokinetics of insulin analogues in a rat model: Oral delivery using $\mathrm{pH}$-responsive nanoparticles vs. subcutaneous injection. Biomaterials 31: 6849-6858.

11. Arbit E (2004) The physiological rationale for oral insulin administration. Diabetes Technol Ther 6: 510-517.

12. Pillai O, Panchagnula R (2001) Insulin therapies - past, present and future Drug Discov Today 6: 1056-1061

13. Sood A, Panchagnula R (2001) Peroral route: an opportunity for protein and peptide drug delivery. Chem Rev 101: 3275-3303.

14. O'Hagan DT (1996) The intestinal uptake of particles and the implications for drug and antigen delivery. J Anat $189: 477-482$.

15. Walker RI, Owen RL (1990) Intestinal barriers to bacteria and their toxins. Annu Rev Med 41: 393-400.

16. Evans DF, Pye G, Bramley R, Clark AG, Dyson TJ, et al. (1988) Measurement of gastrointestinal $\mathrm{pH}$ profiles in normal ambulant human subjects. Gut 29 1035-1041.

17. Langgutha $P$, Bohnera $V$, Heizmanna $H$, Merklea HP, Wolfframb $S$, et al (1997) The challenge of proteolyticenzymes in intestinalpeptidedelivery. J Control Release 46: 39-57.

18. Bernkop-Schnürch A (1998) The use of inhibitory agents to overcome the enzymatic barrier to perorally administered therapeutic peptides and proteins. J Control Release 52: 1-16.

19. Chang LL, Bai JP (1996) Evidence for the existence of insulin-degrading enzyme on the brush-border membranes of rat enterocytes. Pharm Res 13 801-803.

20. Ensign LM, Cone R, Hanes J (2011) Oral drug delivery with polymeric nanoparticles: The gastrointestinal mucus barriers. Adv Drug Deliv Rev.

21. Cone RA (2009) Barrier properties of mucus. Adv Drug Deliv Rev 61: 75-85.

22. Atuma C, Strugala V, Allen A, Holm L (2001) The adherent gastrointestinal mucus gel layer: thickness and physical state in vivo. Am J Physiol Gastrointest Liver Physiol 280: G922-929. 
Citation: Ahmad A, Othman I, Zaini A, Chowdhury EH (2012) Oral Nano-Insulin Therapy: Current Progress on Nanoparticle-Based Devices for Intestinal Epithelium-Targeted Insulin Delivery. J Nanomedic Nanotechnol S4:007. doi:10.4172/2157-7439.S4-007

23. Lai SK, O'Hanlon DE, Harrold S, Man ST, Wang YY, et al (2007) Rapid transport of large polymeric nanoparticles in fresh undiluted human mucus. Proc Natl Acad Sci U S A 104: 1482-1487.

24. des Rieux A, Fievez V, Garinot M, Schneider YJ, Préat V (2006) Nanoparticles as potential oral delivery systems of proteins and vaccines: a mechanistic approach. J Control Release 116: 1-27.

25. Andrews CW, Bennett L, Yu LX (2000) Predicting human oral bioavailability of a compound: development of a novel quantitative structure-bioavailability relationship. Pharm Res 17: 639-644.

26. Goldberg M, Gomez-Orellana I (2003) Challenges for the oral delivery of macromolecules. Nat Rev Drug Discov 2: 289-295.

27. Ma TY, Anderson JM (2006) Tight junctions and the intestinal barrier. Physiology of the gastrointestinal tract. (4th ed.), Academic Press, Burlington, USA

28. Salama NN, Eddington ND, Fasano A (2006) Tight junction modulation and its relationship to drug delivery. Adv Drug Deliv Rev 58: 15-28.

29. Ward PD, Tippin TK, Thakker DR (2000) Enhancing paracellular permeability by modulating epithelial tight junctions. Pharm Sci Technolo Today 3: 346-358.

30. Singh R, Lillard JW Jr (2009) Nanoparticle-based targeted drug delivery. Exp Mol Pathol 86: 215-223.

31. Smart JD (2005) The basics and underlying mechanisms of mucoadhesion. Adv Drug Deliv Rev 57: 1556-1568

32. Lai SK, Wang YY, Hanes J (2009) Mucus-penetrating nanoparticles for drug and gene delivery to mucosal tissues. Adv Drug Deliv Rev 61: 158-171.

33. Hall JB, Dobrovolskaia MA, Patri AK, McNeil SE (2007) Characterization of nanoparticles for therapeutics. Nanomedicine (Lond) 2: 789-803.

34. Farokhzad OC, Langer R (2009) Impact of nanotechnology on drug delivery ACS Nano 3: 16-20.

35. Kumari A, Yadav SK, Yadav SC (2010) Biodegradable polymeric nanoparticles based drug delivery systems. Colloids Surf B Biointerfaces 75: 1-18.

36. Roger E, Lagarce F, Garcion E, Benoit JP (2010) Biopharmaceutical parameters to consider in order to alter the fate of nanocarriers after ora delivery. Nanomedicine (Lond) 5: 287-306.

37. Hillaireau H, Couvreur $P$ (2009) Nanocarriers' entry into the cell: relevance to drug delivery. Cell Mol Life Sci 66: 2873-2896.

38. Pinto-Alphandary $H$, Aboubakar M, Jaillard D, Couvreur P, Vauthier C (2003) Visualization of insulin-loaded nanocapsules: in vitro and in vivo studies after oral administration to rats. Pharm Res 20: 1071-1084

39. Dünnhaupt S, Barthelmes J, Hombach J, Sakloetsakun D, Arkhipova V, et al. (2011) Distribution of thiolated mucoadhesive nanoparticles on intestina mucosa. Int J Pharm 408: 191-199.

40. Makhlof A, Werle M, Tozuka Y, Takeuchi H (2011) A mucoadhesive nanoparticulate system for the simultaneous delivery of macromolecules and permeation enhancers to the intestinal mucosa. J Control Release 149: 81-88.

41. Khutoryanskiy VV (2011) Advances in mucoadhesion and mucoadhesive polymers. Macromol Biosci 11: 748-764

42. Zaki NM, Tirelli N (2010) Gateways for the intracellular access of nanocarriers: a review of receptor-mediated endocytosis mechanisms and of strategies in receptor targeting. Expert Opin Drug Deliv 7: 895-913.

43. Petrus AK, Vortherms AR, Fairchild TJ, Doyle RP (2007) Vitamin B12 as a carrier for the oral delivery of insulin. ChemMedChem 2: 1717-1721.

44. Alsenz J, Russell-Jones GJ, Westwood S, Levet-Trafit B, de Smidt PC (2000) Oral absorption of peptides through the cobalamin (vitamin B12) pathway in the rat intestine. Pharm Res 17: 825-832.

45. Petrus AK, Fairchild TJ, Doyle RP (2009) Traveling the vitamin B12 pathway: oral delivery of protein and peptide drugs. Angew Chem Int Ed Engl 48: 1022 1028.

46. Chalasani KB, Russell-Jones GJ, Yandrapu SK, Diwan PV, Jain SK (2007) A novel vitamin B12-nanosphere conjugate carrier system for peroral delivery of insulin. J Control Release 117: 421-429.

47. Chalasani KB, Russel-Jones GJ, Jain AK, Diwan PV, Jain SK (2007) Effective oral delivery of insulin in animal models using vitamin B12-coated dextran nanoparticles. J Control Release 122: 141-150.
48. Kilpatrick DC, Pusztai A, Grant G, Graham C, Ewen SW (1985) Tomato lectin resists digestion in the mammalian alimentary canal and binds to intestinal vill without deleterious effects. FEBS Lett 185: 299-305.

49. Hussain N, Jani PU, Florence AT (1997) Enhanced oral uptake of tomato lectinconjugated nanoparticles in the rat. Pharm Res 14: 613-618.

50. Florence AT, Hillery AM, Hussain N, Jani PU (1995) Factors affecting the oral uptake and translocation of polystyrene nanoparticles: histological and analytical evidence. J Drug Target 3: 65-70.

51. Zhang N, Ping Q, Huang G, Xu W, Cheng Y, et al. (2006) Lectin-modified solid lipid nanoparticles as carriers for oral administration of insulin. Int J Pharm 327 153-159.

52. Lochner N, Pittner F, Wirth M, Gabor F (2003) Wheat germ agglutinin binds to the epidermal growth factor receptor of artificial Caco-2 membranes as detected by silver nanoparticle enhanced fluorescence. Pharm Res 20: 833-839.

53. Thomas NW, Jenkins PG, Howard KA, Smith MW, Lavelle EC, et al. (1996) Particle uptake and translocation across epithelial membranes. J Anat 189 487-490.

54. Jenkins PG, Howard KA, Blackhall NW, Thomas NW, Davis SS, et al. (1994) The quantification of the absorption of microparticles into the intestinal lymph of Wistar rats. Int J Pharm 102: 261-266.

55. Smith MW, Thomas NW, Jenkins PG, Miller NG, Cremaschi D, et al. (1995) Selective transport of microparticles across Peyer's patch follicle-associated M cells from mice and rats. Exp Physiol 80: 735-743.

56. Nellans HN (1991) (B) Mechanisms of peptide and proteinabsorption: (1) Paracellularintestinal transport: modulation of absorption. Adv Drug Deliv Rev 7: 339-364.

57. Salamat-Miller N, Johnston TP (2005) Current strategies used to enhance the paracellular transport of therapeutic polypeptides across the intestinal epithelium. Int J Pharm 294: 201-216.

58. Ma Z, Lim LY (2003) Uptake of chitosan and associated insulin in Caco2 cell monolayers: a comparison between chitosan molecules and chitosan nanoparticles. Pharm Res 20: 1812-1819.

59. Lin YH, Sonaje K, Lin KM, Juang JH, Mi FL, et al. (2008) Multi-ion-crosslinked nanoparticles with $\mathrm{pH}$-responsive characteristics for oral delivery of protein drugs. J Control Release 132: 141-149.

60. Sonaje K, Chen YJ, Chen HL, Wey SP, Juang JH, et al. (2010) Entericcoated capsules filled with freeze-dried chitosan/poly(gamma-glutamic acid) nanoparticles for oral insulin delivery. Biomaterials 31: 3384-3394.

61. Artursson P, Lindmark T, Davis SS, Illum L (1994) Effect of chitosan on the permeability of monolayers of intestinal epithelial cells (Caco-2). Pharm Res 11: $1358-1361$

62. Sonaje K, Lin YH, Juang JH, Wey SP, Chen CT, et al. (2009) In vivo evaluation of safety and efficacy of self-assembled nanoparticles for oral insulin delivery. Biomaterials 30: 2329-2339.

63. Sonaje K, Lin KJ, Wang JJ, Mi FL, Chen CT, et al. (2010) Self-assembled pH sensitive nanoparticles: a platform for oral delivery of protein drugs. Adv Funct Mater 20: 3695-3700.

64. Su FY, Lin KJ, Sonaje K, Wey SP, Yen TC, et al. (2012) Protease inhibition and absorption enhancement by functional nanoparticles for effective oral insulin delivery. Biomaterials 33: 2801-2811.

65. Mi FL, Wu YY, Lin YH, Sonaje K, Ho YC, et al. (2008) Oral delivery of peptide drugs using nanoparticles self-assembled by poly(gamma-glutamic acid) and a chitosan derivative functionalized by trimethylation. Bioconjug Chem 19: 1248 1255.

66. Jin Y, Song Y, Zhu X, Zhou D, Chen C, et al. (2012) Goblet cell-targeting nanoparticles for oral insulin delivery and the influence of mucus on insulin transport. Biomaterials 33: 1573-1582.

67. Yin L, Ding J, He C, Cui L, Tang C, et al. (2009) Drug permeability and mucoadhesion properties of thiolated trimethyl chitosan nanoparticles in oral insulin delivery. Biomaterials 30: 5691-5700.

68. Leitner VM, Walker GF, Bernkop-Schnürch A (2003) Thiolated polymers: evidence for the formation of disulphide bonds with mucus glycoproteins. Eur $\mathrm{J}$ Pharm Biopharm 56: 207-214. 
Citation: Ahmad A, Othman I, Zaini A, Chowdhury EH (2012) Oral Nano-Insulin Therapy: Current Progress on Nanoparticle-Based Devices for Intestinal Epithelium-Targeted Insulin Delivery. J Nanomedic Nanotechnol S4:007. doi:10.4172/2157-7439.S4-007

Page 10 of 10

69. Sonia TA Sharma CP (2011) In vitro evaluation of N-(2-hydroxy) propyl-3trimethyl ammonium chitosan for oral insulin delivery. Carbohydr Polym 84: 103-109.

70. Cui F, Shi K, Zhang L, Tao A, Kawashima Y (2006) Biodegradable nanoparticles loaded with insulin-phospholipid complex for oral delivery: preparation, in vitro characterization and in vivo evaluation. J Control Release 114: 242-250

71. Davaran S, Omidi Y, Rashidi MR, Anzabi M, Shayanfar A, et al. (2008) Preparation and in vitro evaluation of linear and star-branched PLGA nanoparticles for insulin delivery. J Bioact Compat Polym 23: 115-131.

72. Cui FD, Tao AJ, Cun DM, Zhang LQ, Shi K (2007) Preparation of insulin loaded PLGA-Hp55 nanoparticles for oral delivery. J Pharm Sci 96: 421-427.

73. Wu ZM, Zhou L, Guo XD, Jiang W, Ling L, et al. (2012) HP55-coated capsule containing PLGA/RS nanoparticles for oral delivery of insulin. Int J Pharm 425 : $1-8$.

74. Sharma G, van der Walle CF, Ravi Kumar MN (2011) Antacid co-encapsulated polyester nanoparticles for peroral delivery of insulin: Development, pharmacokinetics, biodistribution and pharmacodynamics. Int J Pharm

75. Zhang X, Sun M, Zheng A, Cao D, Bi Y, et al. (2012) Preparation and characterization of insulin-loaded bioadhesive PLGA nanoparticles for oral administration. Eur J Pharm Sci 45: 632-638.

76. Deutel B, Greindl M, Thaurer M, Bernkop-Schnürch A (2008) Novel insulin thiomer nanoparticles: in vivo evaluation of an oral drug delivery system. Biomacromolecules 9: 278-285.

77. Mesiha MS, Sidhom MB, Fasipe B (2005) Oral and subcutaneous absorption of insulin poly(isobutylcyanoacrylate) nanoparticles. Int J Pharm 288: 289-293.

78. Graf A, Rades T, Hook SM (2009) Oral insulin delivery using nanoparticles based on microemulsions with different structure-types: optimisation and in vivo evaluation. Eur J Pharm Sci 37: 53-61.

79. Foss AC, Goto T, Morishita M, Peppas NA (2004) Development of acrylicbased copolymers for oral insulin delivery. Eur J Pharm Biopharm 57: 163-169.

80. Kumar A, Lahiri SS, Singh H (2006) Development of PEGDMA: MAA based hydrogel microparticles for oral insulin delivery. Int J Pharm 323: 117-124.

81. Iwanaga K, Ono S, Narioka K, Kakemi M, Morimoto K, et al. (1999) Application of surface-coated liposomes for oral delivery of peptide: effects of coating the liposome's surface on the GI transit of insulin. J Pharm Sci 88: 248-252.

82. Damgé C, Maincent $P$, Ubrich N (2007) Oral delivery of insulin associated to polymeric nanoparticles in diabetic rats. J Control Release 117: 163-170.

83. Damgé C, Socha M, Ubrich N, Maincent $P$ (2010) Poly(epsilon-caprolactone)/ eudragit nanoparticles for oral delivery of aspart-insulin in the treatment of diabetes. J Pharm Sci 99: 879-889.

84. Thompson CJ, Tetley L, Cheng WP (2010) The influence of polymer architecture on the protective effect of novel comb shaped amphiphilic poly(allylamine) against in vitro enzymatic degradation of insulin--towards oral insulin delivery. Int J Pharm 383: 216-227.

85. Thompson CJ, Tetley L, Uchegbu IF, Cheng WP (2009) The complexation between novel comb shaped amphiphilic polyallylamine and insulin: towards oral insulin delivery. Int J Pharm 376: 46-55.

86. Thompson C, Cheng WP, Gadad P, Skene K, Smith M, et al. (2011) Uptake and transport of novel amphiphilic polyelectrolyte-insulin nanocomplexes by Caco-2 cells--towards oral insulin. Pharm Res 28: 886-896.

87. Dapergolas G, Gregoriadis G (1976) Hypoglycaemic effect of liposomeentrapped insulin administered intragastrically into rats. Lancet 2: 824-827.

88. Zhang N, Ping QN, Huang GH, Xu WF (2005) Investigation of lectin-modified insulin liposomes as carriers for oral administration. Int J Pharm 294: 247-259.

89. Degim Z, Unal N, EÅŸsiz D, Abbasoglu U (2004) The effect of various liposome formulations on insulin penetration across Caco-2 cell monolayer. Life Sci 75 : 2819-2827.

90. Sarmento B, Martins S, Ferreira D, Souto EB (2007) Oral insulin delivery by means of solid lipid nanoparticles. Int J Nanomedicine 2: 743-749.

91. Thanou M, Verhoef JC, Junginger HE (2001) Oral drug absorption enhancement by chitosan and its derivatives. Adv Drug Deliv Rev 52: 117-126.

92. Chaudhury A, Das S (2011) Recent advancement of chitosan-based nanoparticles for oral controlled delivery of insulin and other therapeutic agents. AAPS PharmSciTech 12: 10-20.

93. Bravo-Osuna I, Vauthier C, Farabollini A, Palmieri GF, Ponchel G (2007) Mucoadhesion mechanism of chitosan and thiolated chitosan-poly(isobuty cyanoacrylate) core-shell nanoparticles. Biomaterials 28: 2233-2243.

94. Yeh TH, Hsu LW, Tseng MT, Lee PL, Sonjae K, et al. (2011) Mechanism and consequence of chitosan-mediated reversible epithelial tight junction opening Biomaterials 32: 6164-6173.

95. Sonaje K, Lin KJ, Tseng MT, Wey SP, Su FY, et al. (2011) Effects of chitosannanoparticle-mediated tight junction opening on the oral absorption of endotoxins. Biomaterials 32: 8712-8721.

96. Smith J, Wood E, Dornish M (2004) Effect of chitosan on epithelial cell tight junctions. Pharm Res 21: 43-49.

97. Prabaharan M (2008) Review paper: chitosan derivatives as promising materials for controlled drug delivery. J Biomater Appl 23: 5-36.

98. Werle M, Takeuchi H, Bernkop-Schnürch A (2009) Modified chitosans for ora drug delivery. J Pharm Sci 98: 1643-1656.

99. Wu L, Ding J (2004) In vitro degradation of three-dimensional porous poly(D,L lactide-co-glycolide) scaffolds for tissue engineering. Biomaterials 25: 5821 5830

100. Krauland AH, Guggi D, Bernkop-Schnürch A (2004) Oral insulin delivery: the potential of thiolated chitosan-insulin tablets on non-diabetic rats. J Control Release 95: 547-555

101. Krauland AH, Bernkop-Schnürch A (2004) Thiomers: development and in vitro evaluation of a peroral microparticulate peptide delivery system. Eur J Pharm Biopharm 57: 181-187.

102. Nakamura K, Murray RJ, Joseph JI, Peppas NA, Morishita M, et al. (2004) Oral insulin delivery using $P(M A A-g-E G)$ hydrogels: effects of network morphology on insulin delivery characteristics. J Control Release 95: 589-599.

103. Xiong XY, Li YP, Li ZL, Zhou CL, Tam KC, et al. (2007) Vesicles from Pluronic/ poly(lactic acid) block copolymers as new carriers for oral insulin delivery. $J$ Control Release 120: 11-17.

104. Weingarten C, Moufti A, Delattre J, Puisieux F, Couvreur P (1985) Protection of insulin from enzymatic degradation by its association to liposomes. Int $J$ Pharm 26: 251-257.

105. Iwanaga K, Ono S, Narioka K, Morimoto K, Kakemi M, et al. (1997) Ora delivery of insulin by using surface coating liposomes: Improvement of stability of insulin in GI tract. Int J Pharm 157: 73-80.

106. Elsayed A, Remawi MA, Qinna N, Farouk A, Badwan A (2009) Formulation and characterization of an oily-based system for oral delivery of insulin. Eur $\mathrm{J}$ Pharm Biopharm 73: 269-279.

107. Woitiski CB, Neufeld RJ, Ribeiro AJ, Veiga F (2009) Colloidal carrier integrating biomaterials for oral insulin delivery: Influence of component formulation on physicochemical and biological parameters. Acta Biomater 5: 2475-2484.

108. Woitiski CB, Neufeld RJ, Veiga F, Carvalho RA, Figueiredo IV (2010) Pharmacological effect of orally delivered insulin facilitated by multilayered stable nanoparticles. Eur J Pharm Sci 41: 556-563.

109. Woitiski CB, Sarmento B, Carvalho RA, Neufeld RJ, Veiga F (2011) Facilitated nanoscale delivery of insulin across intestinal membrane models. Int J Pharm 412: 123-131.

110. Sahay G, Batrakova EV, Kabanov AV (2008) Different internalization pathways of polymeric micelles and unimers and their effects on vesicular transport Bioconjug Chem 19: 2023-2029.

111. Batrakova EV, Kabanov AV (2008) Pluronic block copolymers: evolution of drug delivery concept from inert nanocarriers to biological response modifiers. J Control Release 130: 98-106.

112. Kararli TT (1995) Comparison of the gastrointestinal anatomy, physiology, and biochemistry of humans and commonly used laboratory animals. Biopharm Drug Dispos 16: 351-380.

113. Kreuter J, Müller U, Munz K (1989) Quantitative and microautoradiographic study on mouse intestinal distribution of polycyanoacrylate nanoparticles. In J Pharm 55: 39-45. 
Citation: Ahmad A, Othman I, Zaini A, Chowdhury EH (2012) Oral Nano-Insulin Therapy: Current Progress on Nanoparticle-Based Devices for Intestinal Epithelium-Targeted Insulin Delivery. J Nanomedic Nanotechnol S4:007. doi:10.4172/2157-7439.S4-007

Page 11 of 10

114. Gruber P, Longer MA, Robinson JR (1988) Some biologicalissues in oral, controlleddrugdelivery. Adv Drug Deliv Rev 1.

115. Lamprecht A, Ubrich N, Yamamoto H, Schäfer U, Takeuchi H, et al. (2001)
Biodegradable nanoparticles for targeted drug delivery in treatment of inflammatory bowel disease. J Pharmacol Exp Ther 299: 775-781.

116. Nauck MA, Meier JJ (2011) Pharmacotherapy: GLP-1 analogues and insulin sound the wedding bells? Nat Rev Endocrinol 7: 193-195.

This article was originally published in a special issue, Nanotechnology: Targeted Drug Delivery handled by Editor(s). Dr. Sami M. Nazzal, University of Louisiana at Monroe, USA; Dr. Kytai Troung Nguyen, University of Texas at Arlington, USA 